\title{
Evidence and Policy in Aid-Dependent Settings
}

\author{
Justin Parkhurst, Siobhan Leir, Helen Walls, \\ Elisa Vecchione, and Marco Liverani
}

\section{INTRODUCTION}

As has been noted in earlier chapters of this book, comparative institutional analyses can be particularly difficult when national contexts differ widely. As such, identifying common features in the political or institutional contexts across different settings can be important. One highly relevant contextual feature that is shared across a range of lower income settings is the presence, and potential influence, of international donor

J. Parkhurst $(\bowtie)$

London School of Economics and Political Science, London, UK e-mail: j.parkhurst@lse.ac.uk

S. Leir • H. Walls • E. Vecchione • M. Liverani

London School of Hygiene and Tropical Medicine, London, UK e-mail: siobhan.leir@lshtm.ac.uk; helen.walls@lshtm.ac.uk;

e.vecchione@ucl.ac.uk; marco.liverani@lshtm.ac.uk

(C) The Author(s) 2018

J. Parkhurst et al. (eds.), Evidence Use in Health Policy Making, International Series on Public Policy, https://doi.org/10.1007/978-3-319-93467-9_10 
agencies (or 'aid' agencies) that provide funding and assistance to recipient governments (often classified as 'Official Development Assistance' or ODA). Of course, there are a wide variety of aid modalities and relationships with these agencies in recipient country settings. International donors can be bilateral or multilateral in their orientation (i.e. representing specific governments or collections of countries); they may be private philanthropic (e.g. foundations like the Rockefeller Foundation or Bill and Melinda Gates Foundation); or issue-specific aid mechanisms (e.g. the Global Fund to fight AIDS, Tuberculosis and Malaria; or Gavi - the Vaccine Alliance).

In many parts of the world, aid provision and donor relationships have been seen to have historical strategic and political origins (Van Belle 2004). Lancaster (2008), for instance, argues that most aid - particularly from the US - originated out of cold war diplomacy. While McDougall (2011) argues that Australia's aid programme has aimed to improve security in the pacific region. Yet while each country's arrangements, and historical engagement, with donors will have its own unique features, for comparative analyses it can be a useful starting point to consider shared experiences involved when outside agencies provide financial support for social policies and public services in recipient countries. The role of donors in the use of evidence to inform health policy was thus identified as a theme in three of the GRIP-Health programme case study countries, Cambodia, Ethiopia, and Ghana, where levels of donor assistance (in terms of net Official Development Assistance) were, respectively, $5.1 \%, 6.5 \%$, and $3.0 \%$ of gross national income, at the time of our research (according to 2014 World Bank estimates (World Bank)).

Concerns have been raised, particularly in the international development literature, about the influence that donors may have over domestic policy agendas, policy decisions, and governance arrangements through the aid relationship. Development scholars have often taken a critical stance towards conditionality attached to aid and policy-based lending, in part for its imposition on the sovereignty of recipient countries to make their own policy choices (c.f. Koeberle 2003; Mosley et al. 1995). In the health sector, for instance, Okuonzi and Macrae (1995) ask the fundamental question of 'whose policy is it anyway?' to challenge the influence donors had over priority setting in health in Uganda. Outside the specific confines of health, Chabal (1992) has argued that:

Aid has become an integral part of state policy that is the state takes aid into account when devising and implementing policies. Insofar as it is accountable, then, the state must in part be accountable to outside constituencies 
(donors). Accountability here means that the state meets the conditions under which aid is delivered. Because dependence (aid) is now so central to the survival and operation of African states, accountability to aid-donors is a priority even if it is at the expense of accountability to domestic constituencies. (p. 243)

Conditionality was particularly strongly enforced during the structural adjustment reforms of the 1980s and 1990s, but more recently, there has been a retreat from direct conditions placed on aid. ${ }^{1}$ Yet concerns remain over the ways in which donor influence can undermine state sovereignty, alter political priorities, or impose new power relationships in less explicit, but equally important ways. Swedlund (2013), for instance, evaluates the shift from project based (so-called 'vertical') funding to budgetary support (often termed 'horizontal' funding) in Rwanda and Tanzania to assess if this approach has reduced donor policy influence. He finds that, contrary to popular opinion, donors were also using general budgetary support as a mechanism to shape local policy priorities.

In addition to concerns about influence over policy priorities and choices, some development scholars critique how the international community has fundamentally shaped the governing institutions of low-income countries. The historical legacy of colonialism has provided a starting point for some authors to consider how it provided the political, institutional and administrative bases for the construction of the post-colonial state (c.f. Chazan et al. 1999; Mamdani 1997). It is also well known that international financial institutions and donors have played a major role in steering political and institutional development in some countries, explicitly linking the provision of foreign aid with political reform and constitutional change (Stokke 2013). While approaches to international development have changed over the past two decades, with increasing emphasis on the importance of national governance and stewardship, there are still concerns over external influence on governance structures and systems. Harrison (2001) presents the idea of 'post-conditionality' as a situation in which donor-recipient relationships become more subtle than in past conditionality situations (in terms of direct coercion or explicit demands for policy decisions in return for aid). Instead, in systems of postconditionality, influence is mediated through more informal yet pervasive

\footnotetext{
${ }^{1}$ With some notable exceptions, such as the US government's so-called 'global gag rule' that refuses to provide aid funding to agencies that inform about abortion services in any way, which is repeatedly imposed or rescinded depending on whether a Republican or Democrat is elected as President (Crane and Dusenberry 2004).
} 
practices of administrative guidance, which often embed donor values or ideas into decision structures and reflect power imbalances in doing so. Harrison explains:

Donors do not just impose conditionalities; they also work in routinized fashion at the centre of policy-making. Donor-funded technical assistance introduces not new policies but new methodologies of policy design based on corporate plans, surveys, and closer budgeting and monitoring techniques. (p. 671)

He further notes that this approach works to establish political relations which make the distinction between external and national level actors less useful as donors become involved within multiple forms and processes of decision making (p. 675). Such insights mirror arguments made by Chambers and Pettit (2004) who have described aid as a 'complex system' in which power relations are reinforced through "[o]rganisational norms and procedures, combined with personal behaviour, attitudes and beliefs (p. 137)."

Within the realm of global health and development, such arrangements can place into potential conflict two sets of institutions - national institutions guided by Ministries of Health, serving local populations, and international global health institutions - each with their own different accountability mechanisms or ultimate goals. Some examples of this have been seen elsewhere. Storeng and Béhague (2014), for instance, identified how particular quantitative indicators were embraced or utilised by international maternal health advocates when these helped increase the global profile of their preferred health issue (so-called 'evidence based advocacy'). Béhague et al. (2009) further have explored how the dominant ideas of what an 'evidence based' policy response should be in maternal and neonatal care could impose global policy interests over domestic ones, pushing countries to generic interventions over tailored implementation strategies and serving to legitimate, rather than inform, key policy stakeholders.

Akin to this, Shiffman (2014) has described the advisory role of key global health actors and networks as an exercise in 'epistemic power' in the ways that it establishes the dominance of particular discourses, priorities and approaches in health policy agendas in low-income settings without necessarily raising questions about the legitimacy or accountability of these actors. 
These perspectives thus highlight the salient features of the aid-receiving context in which evidence is both generated and used to guide policy development. We can use these ideas to specifically investigate the institutionalised organisational norms, procedures, behaviours, attitudes and beliefs (to use Chamvers and Pettit's terms) that are established in each setting which shape the utilisation of evidence for health policy decision making.

\section{Evidence Use as a Power/Knowledge Nexus}

Despite the existence of a well-established body of both empirical and conceptual work exploring how donors influence structures, processes, and outcomes of policy decision making, these insights are rarely incorporated in debates about, and recommendations to support, the use of evidence in the health sector. Many global actors use an overtly technical language when referring to the use of evidence, at times mirroring ideas of the public health community: presenting evidence as a technical tool that is principally discussed in terms of how it improves the efficiency or effectiveness of programmatic planning and implementation (c.f. WHO 2004; Yamey and Volmink 2014); and donor funds have increasingly been channelled to programmes aiming to 'improve' evidence use principally based on technical arguments (c.f. iDSI undated; UKAid 2014; ODI 2013).

Seeing the role of evidence as simply technical, however, stands in contrast to critical scholars who have explored the decidedly political nature of evidence utilisation (in both public health and other policy realms). Stewart and Smith (2015) for example have recently discussed how particular 'evidence tools' - including systematic reviews, impact assessments or economic decision-support tools (such as cost-effectiveness analyses) serve political functions in addition to the provision of technical guidance, "primarily in their symbolic value as markers of good decision making"(p. 415). This includes conveying credibility to external audiences as well as providing clear and quantifiable answers to policy questions. Through interviews with public health policy stakeholders, Stewart and Smith found that these tools reflected a high degree of what Weiss (1979) has described as the 'symbolic' use of research - providing signals of what might be considered important, rather than necessarily functioning in the 'problem solving' or 'engineering' roles that many tools are often described as representing. 
Ferlie and McGivern (2013) similarly described the field of evidencebased medicine in the UK as a 'power/knowledge nexus' to explore the political implications of promotion of particular ways to utilise evidence to inform health decisions. In a separate paper, Ferlie and colleagues explain:

power resides in mundane day to day practices, dominant languages, obedient and reformed subjects and taken for granted rationalities. Such power is seen in neutral rather than critical neo Marxist terms: it can constitute a capacity to govern (Clegg, Courpasson, \& Phillips, 2006; Townley, 1998) without crude force, domination or exploitation. (Ferlie et al. 2012, p. 340)

In line with the conceptual approach outlined in Chap. I of this volume, this chapter explores the application of health policy-relevant knowledge as an exercise of power, pulling out insights from three country cases Cambodia, Ghana, and Ethiopia - to explore the use of evidence to inform health policy. Our analysis discusses a set of key themes seen in the mechanisms through which donors may influence policy and politics through evidence utilisation, exploring the political and governance implications seen arising from international donors' promotion or utilisation of particular tools and strategies of evidence application to influence health policy.

\section{Comparative Analysis}

The remainder of this chapter attempts to draw out themes about how donor activities or power relationships can have implications for the use of evidence in health policymaking based on our three country investigations undertaken in aid-dependent settings. Each of these countries is also represented in separate chapters of this book, which provide further information and lines of analysis. So, for example, Chap. 2 presents a comparison of evidence use in Cambodia for three different health policy issues: tobacco control, HIV/AIDS, and performance-based financing including the Government Midwifery Incentive Scheme. The chapter finds that the use of evidence for differing policy issues was best explained by mapping out how the various health policy issues differed in terms of the outcomes of concern to key stakeholders; but also by exploring the structurally established positions of influence that stakeholders had, and the logics held by influential stakeholders over which evidence was held to be relevant to any given outcome. Further work arising from our Cambodia research (published elsewhere) looked more broadly at the routes through which donors could have influence over the health policymaking process 
(analysed through a comparison of Cambodia and Pakistan). That work found that donors could exert influence at each stage of the policy process: priority setting, policy formulation, and policy implementation, monitoring and evaluation. The analysis found that direct funding to preferred policy issues was the most common means of donor influence, but other means of influence arose from control over technical knowledge as well as more indirect influence - such as through financing particular research or evaluations (thus constructing evidence that could be seen as policy relevant), or through recipient country concerns over maintain a good reputation to avoid impacts on non-health areas of concern (e.g. tourism or trade) (Khan et al. 2018).

Influence over institutions and norms by donors can also be seen in the case study from Ghana presented in Chap. 4, which particularly draws out the ways that donors could influence the collection of routine data and indicators to inform annual performance reviews and subsequent sectoral plans. Chapter 3, which presents findings from our Ethiopian case study, looked more specifically at the issue of nutrition policy, and found that the international community's framing of nutrition problems and policy responses could be important factors in helping to explain how evidence was utilised within policymaking processes for that specific issue.

As discussed above, it is important to consider the underlying structural governing dynamics in aid-recipient areas to understand donor influence, including the organisational norms, procedures, or beliefs held that shaping the generation and utilisation of evidence. Through the three case studies in countries reliant on donor support to the health sector, we have thus been able to reflect on multiple ways that donor influence can manifest itself within the structures and processes of evidence use for health policymaking. In this section we draw out three themes that point to particular mechanisms though which donor organisations influence the policy process: through the creation of policy-relevant evidence; through the utilisation of evidence for specific policy processes; and through the construction of systems and routines that shape how evidence informs policy within health policymaking more broadly.

\section{The Generation or Creation of Policy Relevant Evidence}

Health sector planning typically requires assessments of the health status and health care needs of a population as well as knowledge about what is feasible or achievable based on different intervention strategies (Abel-Smith 
1994; Green 2007). For each of these, however, there may be more or less robust bodies of evidence available to provide information about health care needs and intervention possibilities. As social epidemiologist Nancy Krieger (1992) has stated, "If you don't ask, you don't know, and if you don't know, you can't act (p. 412)." In this way, decisions about which data to collect, the identification of a research agenda and the choice of research topics can be seen to be inherently political as it shapes the topics that enter the agenda, and thus which pathways of policy action can be followed (see also: Parkhurst 2016, 2017).

In Cambodia, it was reported that the research agenda and the availability of routine data from the national health information system are driven by external funding, often focused on high profile diseases (such as malaria or HIV/AIDS), and this could result in the neglect of other important health concerns (with issues like hepatitis, road traffic accidents, or dengue fever mentioned). One interviewee further explained that mental health was another key priority in Cambodia, given the historical legacy of the genocide perpetuated in the 1970s; yet research and policy attention to mental health were said to be lacking due to dependence on donor agendas (see (Khan et al. 2018) for more details). Similarly, a recent literature review found that few research reports on non-communicable diseases in Cambodia have been published, despite these accounting for the highest morbidity and mortality rates in the country (Goyet et al. 2015).

In Ethiopia, the influence of donors was said to arise through their funding to local universities conducting research - through which local evidence would then be generated for health topics of interest to donors (with nutrition given as an example). Paralleling a respondent in Cambodia, an Ethiopian interviewee stated that donor research interests might focus on diseases with a high profile on the global health agenda (such as HIV or TB) without work on lesser known areas which might be important from a national perspective, leading to these topics being overlooked when it comes to the drafting of health policies. Research conducted by development partners or NGOs was also seen to be valued by decision makers more highly than that generated solely by Ethiopian scholars, viewing international partners as experts and potentially excluding local sources of evidence, and thus local voices, from having influence on policymaking.

Cambodian interviewers noted other ways that donors might influence the creation of policy relevant evidence. First, donors were seen as influencing which areas of health information systems were strengthened thus building capacity to collect and generate routine data for selected 
areas of health which they prioritised, such as malaria or HIV. Second, donor choice in financing of programme evaluations would again affect which evidence is created in ways that could shape where future policy attention could lie.

\section{Evidence Use Within the Policy Process}

A second theme we explore in our case studies focusses on the use of evidence within different health policymaking processes, to consider the roles or influence of donor agencies within these more specific policy decision situations. One of the most well established (yet often critiqued) mechanisms of donor influence in low-income settings is in the direct funding of particular programmes and shaping of national priorities (Buse and Harmer 2007; Ooms et al. 2008; Sridhar and Tamashiro 2009). While there have been shifts away from such so-called vertical programming, it still does occur in many cases, with large numbers of global bodies directing money to specific health issues. Such arrangements can subsequently have direct impacts on evidence use, however, as those issues which received funding for programmatic use could have increased attention to, or application of, particular forms of evidence.

For example, in Cambodia, we investigated three health (system) topics that have recently received policy attention. Of these, it was HIV/AIDS in comparison to tobacco control or financial performance incentives to health workers - that respondents typically described as having the most robust system to draw on high-quality scientific evidence to guide programmatic decisions; including epidemiological modelling, costeffectiveness data, and scaling up from pilot programme evaluations. A reason given for this, however, was the interest and support of donors to HIV/AIDS in the country. This included provision of financial and human capacity resources to the bodies planning HIV activities, such as the National Centre for HIV/AIDS, Dermatology and STDs.

It may not be surprising that donor interest in HIV enabled a system of evidence use judged by local actors to be better than in other health decisions. Cambodia has limited human resources for the generation and analysis of policy-relevant evidence. In the other two cases explored in Chap. 2 , powerful national interests were seen as dominating the framing of the policy question, which subsequently affected which pieces of evidence were held to be relevant or applied. With the case of tobacco policy, it was industry and national revenue interests that influenced which evidence 
could be brought to bear; while the Prime Minister's office's direct interest in maternal mortality was seen to shape how a midwifery incentive scheme was conceptualised and how it subsequently used evidence. In the case of HIV/AIDS policy in Cambodia, some saw this as presenting a positive development given the limited or piecemeal application of evidence to inform decisions for other health issues. But there are still challenges in the fact that it might only be a sub-set of issues for which there is a robust enough body of evidence generated, reviewed, or applied to justify international interest and funding.

Furthermore, while it was financing of interventions, and of research on priority topics, that affected evidence use for the agenda-setting stage, donors were also seen to have influence on the policy formulation stage in Cambodia. At this stage, influence was seen to derive from donor proficiency in analysing data and using research outputs to inform policies and plans, or in filling knowledge gaps that might exist - either by commissioning additional research or using their own expertise.

Another example of how international actors may have political influence within specific health policy issues can be seen in Ethiopia. Chapter 3 presents a case study of nutrition planning, exploring how the conceptual framing of nutrition by the global community had implications for how particular evidence could inform policy development. For instance it was explained that international stakeholders and processes, including a 2008 Lancet special series on maternal and child undernutrition, led to a common understanding of a need to address nutrition through a multi-sectoral approach. Yet the implications of this were that particular forms of evidence resonated with particular institutionalised logics of appropriateness and were not appropriate for the logics of others, thus hampering efforts to achieve multisectoral policy to address nutrition.

So, for example, it was reported that the Ministry of Agriculture pursued a logic dictated by concern over farm outputs, while the Finance Ministry considered monetary data to justify action from an economic development perspective - in contrast to the typical public health indicators (such as under-five mortality or obesity rates) that are institutionally understood and used to raise malnutrition awareness and priority in global health circles.

The mention of the Lancet's 2008 undernutrition series by our interviewees reflects Shiffman's (2014) recent description of epistemic and normative power in global health. Shiffman specifically identifies the Lancet as "one of the most powerful actors in global health (p. 298)," in 
the ways it has worked to set the global agenda and construct ideas of what should be done in health. Our research described in Chap. 3 illustrates this in practice, showing how a special series of that journal worked to shape the conceptual understanding of malnutrition, with subsequent implications for which evidence was drawn upon and how to shape policy development.

\section{Systems and Routines of Evidence Utilisation}

As noted in the introduction to this chapter, Harrison's (2001) analysis of 'post-conditionality' identified how donor influence has shifted to routinised processes of policy design. While Harrison focusses on Uganda and Tanzania, he points to a set of other African countries that might fit this description (including Ghana). And from a new institutional perspective (c.f. Lowndes 2010; Peters 2005), routinisation would be reflected in the structures, processes, and norms that shape the use of evidence to inform health policy.

For example, the analysis of Ghana presented in Chap. 4 principally focusses on an institutional process and system for data utilisation to inform health policy and planning - specifically exploring how routine local data and locally relevant research evidence are utilised to populate a set of 'indicators' that are then used to evaluate health sector achievement and inform annual formal sector strategic planning meetings. Using routine data to inform annual planning cycles is of course not an unusual idea, yet it was the specific role of donors in defining indicators, and influencing how they were used to assess national policies, that served as mechanisms by which donors could collectively shape the development of national policy. In particular, it was an annual 'health summit' event during which indicators were developed and populated with data to judge policy success, and steer policy directions for the future.

This example echoes forms of influence described by Whitfield (2007) who explains:

Donors exhibit powerful influence over policy not only through conditionality, but also through policy dialogue arenas. Donors have created a plethora of arenas for what they call 'policy dialogue' with government, as well as for coordinating their operations, sharing information and experience, discussing policies, and identifying opportunities to engage government on policy reforms. (p. 145) 
Such policy dialogues can be particularly fertile environments for the introduction of 'evidence' when conceptualised in a technical problem solving manner, with the form, location, and arrangements around such dialogues having implications for power and influence within the local settings.

In Cambodia, however, there were also examples of structured processes and routinised norms that reflected donor influence on the broader institutional environment that shaped evidence use within health policymaking for any number of policy decisions. In Cambodia, for instance, one respondent explained that technical reports were typically published in English, creating an immediate barrier for some local stakeholders to engage with technical evidence. It was also reported that research was driven by funding rather than local demand, which could mean available research could be less relevant to the country. This shows some similarity to issues raised in Ethiopia where it was reported that internationally produced evidence is more respected than that produced internally by national institutions.

\section{Discussion: Influence and Resistance Over Multiple Forms of EVIDENCE Use}

The influence of donors in aid-recipient nations has long been a subject of interest to development scholars, yet rarely have these issues directly been analysed in relation to issues of evidence use within the policy process. Our comparative analysis identified a range of examples and themes through which donor influence could manifest itself in shaping the way evidence was generated or utilised to inform decisions, as well as in the ongoing systems or routines that can influence evidence use as well.

As noted in Chap. 1, Carol Weiss described multiple meanings of research utilisation in the 1970s (c.f. Weiss 1979) - including rational 'problem solving' uses of research, but also how research serves a 'knowledge driven' role to identify problems in the first place, or to influence broader thinking about issues through a so-called 'enlightenment' mechanism. The case studies explored in this chapter illustrate examples of evidence and research use fitting each of these meanings. Influence over evidence generation, for example, could shape the knowledge construction process which serves to identify health problems for policy attention in the first place. The direct support to priority issues, on the other hand, allowed certain topics to have evidence used more robustly in a classic 
problem solving modality. Influence over broader systems of data use, or routinised norms related to expertise and evidence utilisation, on the other hand, might alternatively reflect Weiss' enlightenment ideas.

In these ways we can of course consider donor influence as an exercise of power. The historical concern of some authors over donor control of resources (i.e. funding) certainly was found to be a major influence on which issues received attention, which at times shaped which health issues were seen to have had robust or improved evidence utilisation processes as well. Yet power also could be seen as present in the expert knowledge and capacity in regards to evidence utilisation that international actors possessed, or were perceived as possessing - so called epistemic power linked to scientific expertise.

This said, our country cases also illustrated a number of ways that donor power and influence might be resisted - themes particularly discussed in Ghana and Ethiopia. At the time of the research, Ghana was the only one of our three aid-dependent settings classified as a lower-middle income country (today Cambodia also falls into this classification), but Ghana particularly stood out as having greater local capacity related to evidence generation and use than in Ethiopia or Cambodia. Multiple respondents in Ghana referred to significant research or evidence generative capacity in national bodies, including the Ghana Health Service (GHS) as well as universities. One interviewee stated that the country had a strong desire to be independent from donors in its desire to rely on local data for evaluations; and in another case a representative of a UN body stated that they choose research topics based on those requested by the government.

Notably, there are three well-regarded Health Research Centres within the Research and Development Division of the GHS, serving the northern, middle, and southern regions of the country. According to national documents, these centres conduct research within their designated subregion as per the needs and priorities of the GHS, this information is then used to guide national-level decision making and policy development (Ghana Health Service 2015). All centres are also said to have well established health and demographic surveillance systems and collaborate with a number of international partners and funders (Ghana Health Service 2015; Navrongo Health Research Centre 2016). In contrast, in Cambodia and Ethiopia, there were indications that donors had a strong say over which health topics were researched in the first place. Thus the generation of policy-relevant data could be seen to follow donor interests with 
subsequent implications for policy options. Ghana, however, with its higher capacity and better established research and bureaucratic bodies, appeared less susceptible to influence in this way.

Despite greater local capacity in Ghana, interviewees still mentioned donors could shape policy decisions - achieved through their allocation of resources to specific issues, through a national desire to appease donors so as to maintain budgets, or even through lobbying for preferred policies. One representative of the GHS interviewed noted that there still will be priority allocated to issues based on the power of stakeholders - providing an example of how breast cancer was addressed before cervical cancer in the country, as it affects wealthier individuals, despite representing a lower burden of disease in the country. Yet Ghana has been noted elsewhere for having established a muti-donor budget support mechanism and associated policy dialogue mechanism to improve coordination of aid and maintain national leadership of policymaking in the face of donor proliferation (Pallas et al. 2015). As such there appeared to be a tension between the capacity and strength of local decision making systems and the influence of donors at multiple points.

In Ethiopia, as noted, local capacity was acknowledged as weak for much health planning and decision making. Yet despite the fact that we identified influence over evidence creation and framing of issue responses by donors and international actors, Ethiopian policymaking and planning was understood to be strongly centrally controlled, which seemed to indicate significant resistance to direct influence over decisions or priority setting at times. Indeed, in a recent assessment of potential donor influence on policy in Ethiopia over two decades, Borchgrevink (2008) found particularly strong resistance to influence in the country. A key explanation the author gives is how:

the Ethiopian regime is independent-minded, proud, and unwilling to bow to the whims and wishes of donors and the international community in general. The [ruling coalition] has learnt self-reliance during a long guerrilla struggle, has a strong commitment to its own development model with a basis in Marxism-Leninism, and a perhaps healthy distrust of the reliability of donors. (p. 216)

This, in combination with a lack of donor coordination or consistency and the lack of significant threat to change the regime, are used by Borchgrevink to explain that "donors have been relatively powerless to 
influence Ethiopian policies (p. 215).” Indeed, one representative of a UN agency stated that it was still the Ethiopian government who decides how to use the results of research programmes, for instance, even if research was supported externally. This difficulty to influence the government was also reflected in several of our interviews, where the strength of the government was seen to limit the influence donors could have - both on policy agendas, but also on the roles that evidence plays in planning.

Ultimately, insights from multiple countries illustrate balances between donor influence and national country resistance or control over policymaking. Agendas could be directly shaped by donor funds, or more indirectly influenced through creation of policy-relevant evidence. Yet the extent and impact of each of these was contextually determined, influenced by government capacity, systems, and control over aspects of decision making in the health sector. Strategic forms of resistance to influence would also reflect the idea of aid as a 'game' situation, explored in earlier work on aid conditionality by Mosely et al. (1995) in which donors and recipients are conceptualised as pursuing different goals, basing behaviour on the expected response of the other party and potential trade-offs as a result.

\section{Conclusions}

While the use of evidence to inform health policy has often been discussed in technical terms, critical policy scholars have noted how such conceptualisations may mask or ignore important aspects of policymaking - including how evidence promotion or utilisation risks depoliticising the policy process - both by obscuring the fundamental value-based choices that policy makers must consider and trade off, as well as obscuring the governance implications that may arise from the different ways evidence may be used to steer or shape ultimate policy decisions. Exploring these concerns through the specific context of aid-dependent settings, however, adds new insights into how power dynamics can play out in multiple ways affecting not only specific policy decision making, but also through the underlying governing institutional structures that shape how evidence is created, selected, or interpreted to inform policy decisions.

In our comparative reflection presented above, the political-economy of aid and development has been shown to manifest itself through a number of more or less visible processes of evidence utilisation. Donor agencies not only use evidence to essentially promote desired policy choices and agenda topics, but they similarly have influence over which policy- 
relevant evidence bases are created in the first place by funding research, strengthening select routine data sources, or undertaking programmatic evaluations of desired interventions. They further have been shown to have influence over the ways that pieces of evidence are interpreted in decision making fora at times, illustrating the power dynamics within decisions around which evidence is relevant for what policy and planning considerations. Finally, donors at times work to construct institutionalised systems and processes, the continuing performance of which may work to prioritise particular problems, solutions, or power relationships within the health sector. In all these ways we can see the importance of critically investigating the power and governance implications of evidence promotion and use, particularly in low and middle income settings which have historically had less research in these areas, yet which clearly show important dynamics as well due to the political dynamics of the aid donorrecipient relationship.

\section{REFERENCES}

Abel-Smith, Brian. 1994. An introduction to bealth: Policy, planning and financing. London: Longman.

Behague, Dominique, Charlotte Tawiah, Mikey Rosato, Telesphore Some, and Joanna Morrison. 2009. Evidence-based policy-making: The implications of globally-applicable research for context-specific problem-solving in developing countries. Social Science \& Medicine 69 (10): 1539-1546.

Borchgrevink, Axel. 2008. Limits to donor influence: Ethiopia, aid and conditionality. Forum for Development Studies 35 (2): 195-220. https://doi.org/10.10 80/08039410.2008.9666409.

Buse, Kent, and Andrew M. Harmer. 2007. Seven habits of highly effective global public-private health partnerships: Practice and potential. Social Science \& Medicine 64 (2): 259-271.

Chabal, Patrick. 1992. Power in Africa. London: Macmillian Press Ltd.

Chambers, Robert, and Jethro Pettit. 2004. Shifting power to make a difference. In Inclusive aid: Changing power and relationships in international development, ed. Leslie Groves and Rachel Hinton, 137-162. London: Earthscan.

Chazan, Naomi, Peter Lewis, Robert Mortimer, Donald Rothchild, and Stephen John Stedman. 1999. Politics and society in contemporary Africa. 3rd ed. Boulder: Lynne Rienner Publishers, Inc.

Crane, Barbara B., and Jennifer Dusenberry. 2004. Power and politics in international funding for reproductive health: The US global gag rule. Reproductive Health Matters 12 (24): 128-137. https://doi.org/10.1016/ S0968-8080(04)24140-4. 
Ferlie, Ewan, and Gerry McGivern. 2013. Bringing Anglo-governmentality into public management scholarship: The case of evidence-based medicine in UK health care. Journal of Public Administration Research and Theory. https:// doi.org/10.1093/jopart/mut002.

Ferlie, Ewan, Gerry Mcgivern, and Louise FitzGerald. 2012. A new mode of organizing in health care? Governmentality and managed networks in cancer services in England. Social Science \& Medicine 74 (3): 340-347.

Ghana Health Service. 2015. Research and development division: Research centres. http://www. ghanahealthservice .org/division-scat.php?ghsdid=11\&ghsscid=68. Accessed 28 Nov 2016.

Goyet, Sophie, Socheat Touch, Por Ir, Sovannchhorvin SamAn, Thomas Fassier, Roger Frutos, Arnaud Tarantola, and Hubert Barennes. 2015. Gaps between research and public health priorities in low income countries: Evidence from a systematic literature review focused on Cambodia. Implementation Science 10 (1): 32 .

Green, Andrew. 2007. An introduction to health planning for developing health systems. Oxford: Oxford University Press.

Harrison, Graham. 2001. Post-conditionality politics and administrative reform: Reflections on the cases of Uganda and Tanzania. Development and Change 32 (4): 657-679.

iDSI. undated. About us. NICE-International. http://www.idsihealth.org/ about-us/. Accessed 8 June 2015.

Khan, Mishal S., Ankita Meghani, Marco Liverani, Imara Roychowdhury, and Justin Parkhurst. 2018. Influences of external donors on national health policy processes: Experiences of local policy actors in Cambodia and Pakistan. Health Policy and Planning. 33 (2): 215-223. https://doi.org/10.1093/heapol/czxl45

Koeberle, Stefan G. 2003. Should policy-based lending still involve conditionality? The World Bank Research Observer 18 (2): 249-273. https://doi.org/10.1093/ wbro/lkg009.

Krieger, Nancy. 1992. The making of public health data: Paradigms, politics, and policy. Journal of Public Health Policy 13: 412-427.

Lancaster, Carol. 2008. Foreign aid: Diplomacy, development, domestic politics. Chicago: University of Chicago Press.

Lowndes, Vivian. 2010. The institutional approach. In Theory and methods in political science, ed. David Marsh and Gerry Stoker, 6-79. Basingstoke: Palgrave Macmillian.

Mamdani, Mahmood. 1997. Citizen and subject: Decentralised despotism and the legacy of late colonialism. Delhi: Oxford University Press.

McDougall, Derek. 2011. Australia's engagement with its 'near abroad': A change of direction under the Labor government, 2007-10? Commonwealth o Comparative Politics 49 (3): 318-341. https://doi.org/10.1080/14662043. 2011.582735 . 
Mosley, Paul, Jane Harringan, and John Toye. 1995. Aid and power: Second edition: The World Bank \& policy-based lending. Vol. 1. London: Routledge.

Navrongo Health Research Centre. 2016. Partners \& funders. http://www. navrongo-hrc.org/content/partners-funders. Accessed 28 Nov 2016.

ODI. 2013. Australia-Indonesia partnership for pro-poor policy: The knowledge sector initiative. Overseas Development Institute. http://www.odi.org/ projects / 2677-australia-indonesia-partnership-pro-poor-policy-knowledgesector-initiative. Accessed 8 June 2015.

Okuonzi, Sam Agatre, and Joanna Macrae. 1995. Whose policy is it anyway? International and national influences on health policy development in Uganda. Health Policy and Planning 10 (2): 122-132.

Ooms, Gorik, Wim Van Damme, Brook K. Baker, Paul Zeitz, and Ted Schrecker. 2008. The 'diagonal' approach to Global Fund financing: A cure for the broader malaise of health systems? Globalization and Health 4 (6): 1-7.

Pallas, Sarah Wood, Justice Nonvignon, Moses Aikins, and Jennifer Prah. 2015. Responses to donor proliferation in Ghana's health sector: A qualitative case study. Bulletin of the World Health Organization 93: 11-18.

Parkhurst, Justin. 2017. The politics of evidence: from evidence based policy to the good governance of evidence. Abingdon: Routledge.

Parkhurst, Justin O. 2016. Appeals to evidence for the resolution of wicked problems: The origins and mechanisms of evidentiary bias. Policy Sciences 49 (4): 373-393. https://doi.org/10.1007/s11077-016-9263-z.

Peters, Guy. 2005. Institutional theory in political science. London: Continuum.

Shiffman, Jeremy. 2014. Knowledge, moral claims and the exercise of power in global health. International Journal of Health Policy and Management 3 (6): 297-299. https://doi.org/10.15171/ijhpm.2014.120.

Sridhar, Devi, and Tami Tamashiro. 2009. Vertical funds in the health sector: Lessons for education from the Global Fund and GAVI. United Nations Educational, Scientific and Cultural Organization (UNESCO).

Stewart, Ellen, and Katherine E. Smith. 2015. 'Black magic' and 'gold dust': The epistemic and political uses of evidence tools in public health policy making. Evidence \& Policy: A Journal of Research, Debate and Practice 11 (3): 415-437. https://doi.org/10.1332/174426415X14381786400158.

Stokke, Olav. 2013. Aid and political conditionality. London: Frank Cass \& Co. Ltd.

Storeng, Katerini T., and Dominique P. Béhague. 2014. "Playing the numbers game": Evidence-based advocacy and the technocratic narrowing of the safe motherhood initiative. Medical Anthropology Quarterly 28 (2): 260-279.

Swedlund, Haley J. 2013. From donorship to ownership? Budget support and donor influence in Rwanda and Tanzania. Public Administration and Development 33 (5): 357-370.

UKAid. 2014. BCURE building capacity to use research evidenve. http:// wordpress.com/. Accessed 2 Oct 2014. 
Van Belle, Douglas A. 2004. Media, bureaucracies, and foreign aid: A comparative analysis of the United States, the United Kingdom, Canada, France and Japan. New York: Palgrave Macmillan.

Weiss, Carol H. 1979. The many meanings of research utilization. Public Administration Review 39 (5): 426-431.

Whitfield, Lindsay. 2007. Identity construction in development practices: The government of Ghana, civil society, private sector, and development partners. In Professional identities: Policy and practice at work in business and bureaucracy, ed. Shirley Ardener and Fiona Moore, 143-160. New York: Berghahn Books.

WHO. 2004. World report on knowledge for better health: Strengthening health systems. Geneva: World Health Organization.

World Bank. Net ODA received (\% of GNI). https://data.worldbank.org/ indicator/DT.ODA.ODAT.GN.ZS. Accessed 12 Jan 2017.

Yamey, Gavin, and Jimmy Volmink. 2014. An argument for evidence-based policymaking in global health. In The handbook of global health policy, ed. Garett W. Brown, Gavin Yamey, and Sarah Wamala, 133-155. Chichester: Wiley-Blackwell.

Open Access This chapter is licensed under the terms of the Creative Commons Attribution 4.0 International License (http://creativecommons.org/licenses/ by $/ 4.0 /)$, which permits use, sharing, adaptation, distribution and reproduction in any medium or format, as long as you give appropriate credit to the original author(s) and the source, provide a link to the Creative Commons license and indicate if changes were made.

The images or other third party material in this chapter are included in the chapter's Creative Commons license, unless indicated otherwise in a credit line to the material. If material is not included in the chapter's Creative Commons license and your intended use is not permitted by statutory regulation or exceeds the permitted use, you will need to obtain permission directly from the copyright holder.

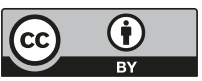

